\title{
A VARIAÇÃO NA CONSTRUÇÃO RELACIONAL DE MUDANÇA DE ESTADO: FICAR, TORNAR-SE E VIRAR $^{1}$
}

Bruna Gois Pavão Ferreira (UFRJ)

Resumo: O objetivo deste trabalho é descrever uma parcela da rede da construção relacional de mudança de estado no Português Brasileiro, analisando a variação que ocorre no uso dos verbos ficar, tornar-se e virar nesse tipo de construção. Para tanto, foram considerados apenas dados com sujeito (animado ou não animado) e os verbos em estudo seguidos de predicativo sob as formas de sintagma adjetival ou sintagma nominal. Foram descartados dados de construções impessoais e com sintagmas oracionais e sob a forma de sintagmas preposicionados ou adverbiais, além de construções em que os verbos em estudo integravam locuções verbais. A abordagem escolhida para nortear esta pesquisa é a Gramática de Construções Baseada no Uso (BYBEE, 2010, 2013; CROFT, 2001; GOLDBERG, 1995, 2013; TRAUGOTT \& TROUSDALE, 2013; dentre outros), que considera a construção gramatical (pareamento de forma e significado) como unidade básica da língua, levando em consideração o uso, e apresenta um modelo de gramática como rede de construções interconectadas. Assim, algumas das questões a que se busca responder são: (i) quais as diferenças e similaridades no uso dos verbos ficar, tornarse e virar na construção relacional de mudança de estado?; (ii) como se dá a variação/alternância entre tais verbos nesse tipo de construção? Como objetivos específicos, destacam-se: (i) a identificação dos padrões de uso com base na frequência e nas relações de forma e/ou significado por semelhanças de família existentes entre tais construções; (ii) a configuração morfossintática da construção relacional de mudança de estado; (iii) suas instâncias de uso; (iv) as diferenças semânticopragmáticas entre as construções com ficar, tornar-se e virar.

Palavras-chave: Gramática de Construções Baseada no Uso; Construção Relacional de Mudança de Estado; Variação.

Abstract: The purpose of this paper is to describe a portion of the network of relational construction of state change in Brazilian

1 Título em inglês: "The variation in relational construction of change of state: ficar, tornar-se e virar" 
Portuguese, analyzing the variation that occurs in the use of verbs ficar, tornar-se and virar in this type of construction. For that, only data with subject (animated or not animated) and the verbs in study followed by predicative under the forms of adjectival syntagma or noun phrase were considered. Data of impersonal constructions and with phrases and in the form of prepositional or adverbial phrases were discarded, as well as constructions in which the verbs in study included verbal phrases. The approach chosen to guide this research is the Usage-Based Construction Grammar (BYBEE, 2010, 2013, CROFT, 2001, GOLDBERG, 1995, 2013, TRAUGOTT \& TROUSDALE, 2013, among others), which considers grammatical construction (form and meaning) as the basic unit of the language, taking into account the use, and presents a grammar model as network of interconnected constructions. Thus, some of the questions that are sought to answer are: (i) what differences and similarities in the use of verbs ficar, tornar-se and virar in the relational construction of change of state?; (ii) how does the variation / alternation between such verbs occur in this type of construction? Specific objectives include: (i) identification of patterns of use based on frequency and relationships of form and / or meaning by family similarities between such constructions; (ii) the morphosyntactic configuration of the relational construction of change of state; (iii) its instances of use; (iv) the semantic-pragmatic differences between constructions with ficar, tornar-se and virar.

Keywords: Usage-Based Construction Grammar; Relational State Change Construction; Variation.

\section{INTRODUÇÃO}

Esta pesquisa é motivada pela pouca quantidade de estudos sobre a variação na construção relacional de mudança de estado. Na tradição gramatical, os verbos que compõem esse tipo de construção são chamados de verbos de ligação, que são considerados vazios de significado, pois funcionariam apenas como elo entre o sujeito e seu predicativo. Além disso, na escola, apenas é apresentada, geralmente, uma 
lista de verbos mais prototípicos (ser, estar, ficar, permanecer, tornar-se, continuar, parecer) aos alunos, sem levar em conta outros verbos que podem integrar esse tipo de construção. Também não são estudadas de forma detalhada as diferentes nuances de sentido que tal construção pode apresentar, como a mudança de estado, analisada neste trabalho.

Este trabalho objetiva contribuir para a descrição do PB ao analisar a construção relacional de mudança de estado compatibilizada com três verbos diferentes (ficar, tornar-se e virar), mostrando que ela pode exprimir algumas nuances de sentido, com diferenças aspectuais e de registro, que serão analisadas aqui. Para exemplificar o objeto de estudo deste trabalho, seguem alguns dados dos corpora utilizados na pesquisa:

(1) "Desde que Bianca ganhou Emily e a bebê ficou internada na UTI, Eduardo está na casa da avó materna."

(2) "Agora mostramos como esse diálogo aplicado à escola, como comunidade de prática, pode fazer com que o aluno se torne um membro periférico legítimo."

(3) “Novo sistema para roubar carros virou moda em Portugal."

\section{PRESSUPOSTOS TEÓRICOS}

A Gramática de Construções Baseada no Uso (GCBU) considera a construção gramatical como a unidade básica da língua, uma vez que consiste em um pareamento 
convencionalizado de forma e significado. As principais proposições dessa abordagem são: (i) não há separação entre léxico e gramática, e sim uma rede de construções; (ii) processos cognitivos gerais contribuem para a compreensão da linguagem, ou seja, processos não específicos apenas à linguagem (como analogia, categorização, etc.); (iii) a análise do uso é essencial para a compreensão do conhecimento linguístico, pois a experiência de uso afeta a representação cognitiva subjacente. Dessa forma, o conhecimento linguístico é maleável por ser afetado pelo uso durante toda a vida do falante.

Essa abordagem concebe o conhecimento linguístico como uma rede de construções, ou seja, como um conjunto de elementos interconectados. Por constituir uma rede, a gramática de uma língua apresenta relações de herança (GOLDBERG, 1995), que motivam as propriedades das construções particulares. Goldberg (1995) apresenta quatro tipos de herança: (i) herança por polissemia - quando uma construção é uma extensão semântica de outra; (ii) herança por subparte - quando parte de uma construção pode existir de forma independente, em uma construção à parte; (iii) herança por instanciação-quando uma construção específica instancia outra; (iv) herança por extensão metafórica quando o sentido da construção primitiva é projetado para 
outro domínio na nova construção. Esses tipos de herança possibilitam determinar as diferenças e similaridades entre construções relacionadas. Neste trabalho, leva-se em consideração a herança por polissemia, uma vez que há, pelo menos, três formas para a construção relacional de mudança de estado.

Este trabalho adota alguns conceitos relevantes na abordagem construcionista, como a frequência de uso na constituição e generalização das formas gramaticais para relacioná-las em redes construcionais, organizadas com base nas semelhanças de família, ou seja, os membros de uma determinada categoria podem estar relacionados sem que compartilhem um conjunto de propriedades em comum, como nos termos da categoria aristotélica clássica, mas uma cadeia de similaridades diretas ou indiretas. A frequência de uso é dividida em token e type: a frequência token corresponde à quantidade de ocorrências de cada verbo em análise em uma construção relacional de mudança de estado, enquanto a frequência type se refere aos tipos de ocorrências encontrados com cada verbo, como por exemplo, sujeito + tornar-se + SN e sujeito + tornar-se + SAdj. constituem dois types diferentes.

Um princípio que rege este trabalho é o Princípio da Não Sinonímia (GOLDBERG, 1995), que afirma que, se duas construções são sintaticamente distintas, elas devem ser 
semânticas ou pragmaticamente distintas, e um dos aspectos pragmáticos citados por Goldberg é o aspecto estilístico da construção, como o registro, que constitui um dos parâmetros de análise neste trabalho. Dessa forma, como a construção em análise apresenta formas diferentes para um mesmo significado (mudança de estado), é importante identificar as diferenças discursivo-pragmáticas.

Como o propósito deste trabalho é o estudo da variação, é importante destacar, também, a Sociolinguística Variacionista, que concebe a língua em um contexto sociocultural, no qual seus usuários mantêm relações sociais e interacionais. Segundo essa abordagem, a principal característica da língua é a variação, suscetível de ser estudada e sistematizada. Além disso, pressupõe que toda variação é motivada, uma vez que o emprego de uma forma linguística no lugar de outra ocorre devido a regras variáveis, condicionadas por fatores extralinguísticos e intralinguísticos. Neste trabalho, serão investigadas as formas que se alternam (ficar, tornar-se e virar) em um mesmo contexto (mudança de estado) e as motivações para que a variação ocorra.

\section{HIPÓTESES E PROCEDIMENTOS METODOLÓGICOS}

As hipóteses que norteiam a pesquisa são as de que haveria: (i) uma relação entre o tipo de sintagma predicativo 
e a escolha do verbo. As construções com ficar apresentariam mais predicativos sob a forma de sintagma adjetival e as construções com tornar-se e virar apresentariam mais predicativos sob a forma de sintagma nominal; (ii) uma relação entre o tipo de sujeito (animado ou não animado) e o verbo de mudança de estado escolhido para compor a construção. Com ficar, haveria maior ocorrência de sujeitos animados, já com tornar-se e virar, maior ocorrência de sujeitos inanimados; (iii) uma diferença quanto ao grau de formalidade/registro. As construções com tornar-se parecem mais formais que as construções com virar e as com ficar seriam utilizadas em ambos os contextos; (iv) uma diferença semântico-aspectual entre as construções com ficar e tornarse. As construções com ficar indicariam mudanças mais transitórias e as construções com tornar-se e virar indicariam mudanças mais permanentes.

Os corpora escolhidos para a coleta de dados foram divididos de acordo com o registro: (i) formal - artigos acadêmicos de quatro revistas das áreas de ciência, tecnologia, saúde e educação; (ii) informal - relatos de viajantes sobre pontos turísticos e hotéis do Rio de Janeiro (Booking, Mundi e TripAdvisor) e reclamações de clientes sobre aparelhos celulares (Reclame Aqui). 
Foram descartados dados de construções impessoais, com sujeito oracional, construções com predicativo sob a forma de sintagmas preposicionados e adverbiais, dados que expressavam outros sentidos (que não fossem mudança de estado), além de construções em que os verbos em estudo integravam locuções verbais, para que o verbo auxiliar não influenciasse a semântica da construção. Alguns exemplos de dados excluídos são:

(4) “Desta análise ficou nítido que a espessura da alma era um parâmetro a ser considerado em conjunto com o parafuso de $19 \mathrm{~mm}$ de diâmetro."

(5) "Além dos procedimentos de controle de qualidade do fabricante, o material e a qualidade do serviço devem ficar permanentemente sujeitos à inspeção por parte de profissionais qualificados, representantes do proprietário da obra."

(6) "Comparando esses dois metais com a legislação de potabilidade e a Organização Mundial da Saúde (WHO, 1993), a mediana dos valores ficou dentro dos padrões estabelecidos pelas portarias."

(7) "Passeio imperdível a turistas e cariocas. Final do dia incrível, com uma vista fantástica. Ficara para sempre na memória."

Em (4), tem-se uma construção com sujeito oracional ("que a espessura..."), dificultando a identificação de sua animacidade. Em (5), ficar integra uma locução verbal ("devem ficar"), influenciando a semântica da construção. O exemplo 
(6) apresenta predicativo sob a forma de Sadv. ("dentro dos padrões estabelecidos pelas portarias"), com uma semântica de localização. Por último, em (7), há um predicativo sob a forma de Sprep. ("na memória”), que apresenta semântica de localização também.

O trabalho foi realizado em duas etapas: (a) coleta de dados e sua análise qualitativa e quantitativa; (b) aplicação de testes de percepção/atitudes linguísticas e sua análise.

Primeiramente, foram analisados os dados coletados de acordo com: (i) o verbo compatibilizado à construção - ficar, tornar-se ou virar; (ii) o tipo de sintagma predicativo - SN ou SAdj.; (iii) o tipo de sujeito - animado ou não animado.

Na segunda etapa, foram elaborados e aplicados dois testes de percepção/atitudes linguísticas, que permitiram identificar generalizações reveladoras de possíveis relações entre avaliação subjetiva e motivação para a escolha consciente de formas linguísticas alternativas. Assim, foram escolhidos 12 dados para a elaboração do primeiro teste, que tinha por objetivo identificar a escolha do falante por um dos três verbos (ou mais de um deles, se julgasse pertinente) para compor a construção relacional de mudança de estado. O objetivo foi testar a hipótese de que o registro (formal/informal) é um dos fatores que influenciam a escolha de um dos verbos em estudo para integrar a construção de mudança de estado. 
Em seguida, foi elaborado outro teste, com seis dados diferentes dos utilizados no primeiro teste, para avaliar o sentido da construção com cada verbo, indicando se é uma mudança de estado mais permanente ou mais transitória. Os dois testes foram aplicados a dez pessoas leigas, com Ensino Médio completo ou com Ensino Superior (completo ou em curso). Por serem testes de múltipla escolha, foi solicitado aos voluntários que justificassem, de forma opcional e discursivamente, suas respostas, a fim de identificar o que os levou a optar por um verbo e não por outro para compor a construção.

\section{RESULTADOS}

Foram coletados e analisados 211 dados, de acordo com o verbo compatibilizado à construção - ficar, tornar-se ou virar, o tipo de sintagma predicativo - SN ou SAdj. e o tipo de sujeito - animado ou não animado. Em seguida, alguns desses dados foram analisados por participantes leigos em dois diferentes testes de percepção/atitudes, a fim de analisar o grau de formalidade (registro formal ou informal) e o aspecto (permanente ou transitório) das construções com cada verbo em estudo (ficar, tornar-se e virar).

\subsection{Análise das amostras de dados}

A primeira etapa da pesquisa consistiu na análise das amostras de dados. Os corpora escolhidos para a coleta de 
dados foram divididos de acordo com o registro: (i) formal artigos acadêmicos e jornal $O$ Globo; (ii) informal - relatos de viajantes sobre pontos turísticos e hotéis do Rio de Janeiro (Booking, Mundi e TripAdvisor), reclamações de clientes sobre aparelhos celulares (Reclame Aqui) e jornal Extra.

Os dados coletados foram analisados de acordo com o verbo, o tipo de sintagma predicativo (SAdj. ou SN) e o tipo de sujeito (animado ou não animado).

A tabela 1 apresenta os corpora (divididos em registro formal e registro informal) e a quantidade de dados por verbo. 


\begin{tabular}{|c|c|c|c|c|}
\hline & Fontes & FICAR & TORNAR-SE & VIRAR \\
\hline \multirow[t]{5}{*}{$\begin{array}{l}\text { Registro } \\
\text { formal } \\
\text { (Artigos } \\
\text { acadêmicos } \\
\text { e jornal) }\end{array}$} & $\begin{array}{l}\text { Revista } \\
\text { Eletrônica } \\
\text { de } \\
\text { Engenharia } \\
\text { Civil }\end{array}$ & 07 & 09 & 0 \\
\hline & $\begin{array}{l}\text { Revista Ciência } \\
\text { \& Engenharia }\end{array}$ & 10 & 06 & 1 \\
\hline & $\begin{array}{l}\text { Revista } \\
\text { Educação e } \\
\text { Pesquisa }\end{array}$ & 12 & 28 & 0 \\
\hline & $\begin{array}{l}\text { Revista Ciência } \\
\text { \& Saúde }\end{array}$ & 06 & 07 & 0 \\
\hline & $\begin{array}{l}\text { Jornal O Globo } \\
\text { online }\end{array}$ & 20 & 18 & 10 \\
\hline TOTAL: & & & & \\
\hline 134 dados & & 55 & 68 & 11 \\
\hline
\end{tabular}




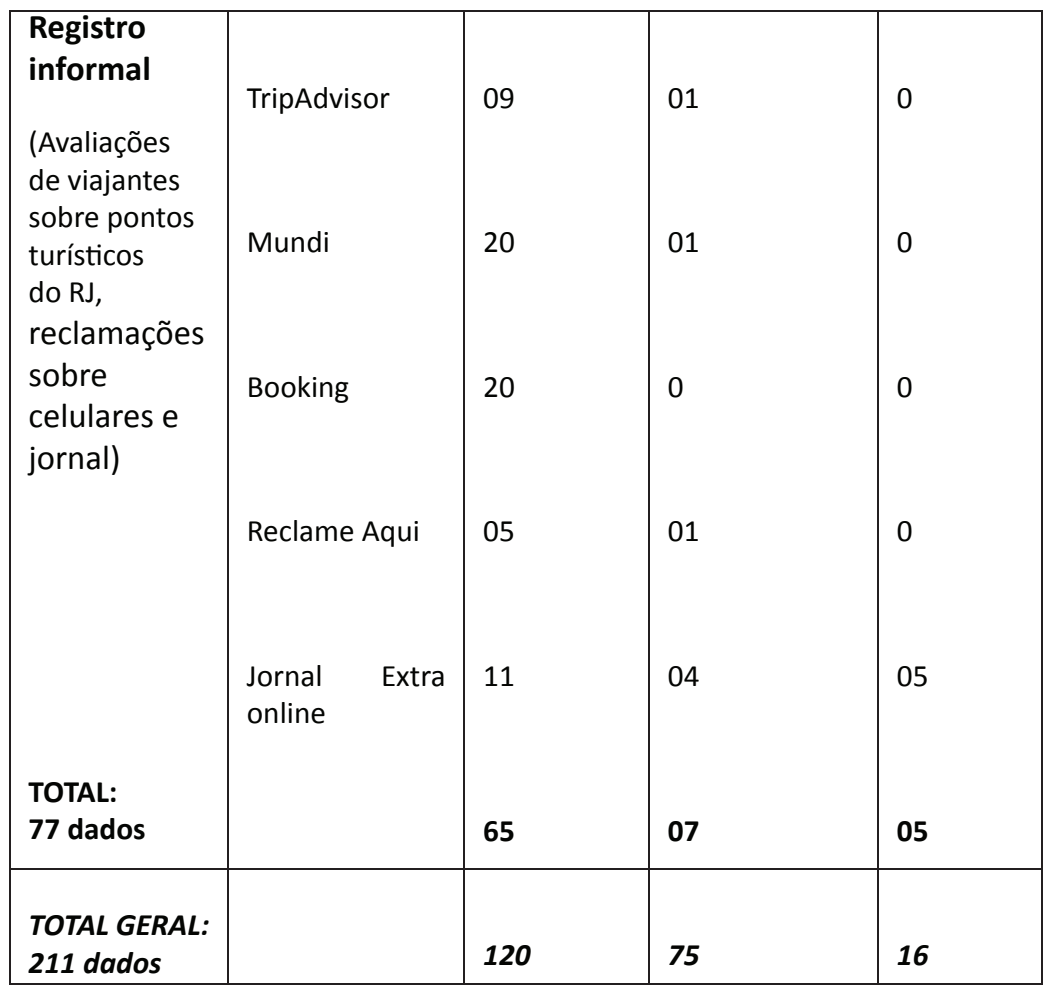

Tabela 1 - Apresentação dos corpora e distribuição dos dados

Em relação ao tipo de sintagma predicativo, no registro formal, foram obtidos os seguintes resultados (tabela 2):

\begin{tabular}{|l|c|c|c|}
\hline \multicolumn{1}{|c|}{ Registro formal } & FICAR & TORNAR-SE & VIRAR \\
\hline PREDICATIVO SN & 0 & $\underline{\mathbf{4 1}}$ & $\underline{\mathbf{1 1}}$ \\
\hline PREDICATIVO SADJ & $\underline{\mathbf{5 5}}$ & 27 & 0 \\
\hline TOTAL: & $\mathbf{5 5}$ & $\mathbf{6 8}$ & $\mathbf{1 1}$ \\
\hline
\end{tabular}

Tabela 2 - Tipo de sintagma predicativo no registro formal 
A hipótese de que haveria uma relação entre o tipo de sintagma predicativo e a escolha do verbo foi confirmada quanto a ficar, que só apareceu sob a forma de SAdj. nos corpora. Quanto ao verbo tornar-se, predominou o predicativo sob a forma de SN. Com virar, só ocorreu predicativo sob a forma de SN. Dessa forma, no registro formal, os dados apresentaram-se conforme o esperado.

Em relação ao tipo de sintagma predicativo, no registro informal, foram obtidos os seguintes resultados (tabela 3):

\begin{tabular}{|l|c|c|c|}
\hline \multicolumn{1}{|c|}{ Registro informal } & FICAR & TORNAR-SE & VIRAR \\
\hline PREDICATIVO SN & 0 & $\underline{\mathbf{0 6}}$ & $\underline{\mathbf{0 4}}$ \\
\hline PREDICATIVO SADJ & $\underline{\mathbf{6 5}}$ & 01 & 01 \\
\hline TOTAL: & $\mathbf{6 5}$ & $\mathbf{0 7}$ & 05 \\
\hline
\end{tabular}

Tabela 3 - Tipo de sintagma predicativo no registro informal

Os resultados do tipo de sintagma predicativo no registro informal foram bastante semelhantes aos do registro formal.

Quanto ao tipo de sujeito (animado ou não animado), no registro formal, foram obtidos os seguintes resultados (tabela 4): 


\begin{tabular}{|l|c|c|c|}
\hline \multicolumn{1}{|c|}{ Registro formal } & FICAR & TORNAR-SE & VIRAR \\
\hline SUJ. ANIMADO & 23 & 14 & 04 \\
\hline SUJ. NÃO ANIMADO & $\underline{\mathbf{3 2}}$ & $\underline{\mathbf{5 4}}$ & $\underline{\mathbf{0 7}}$ \\
\hline TOTAL: & $\mathbf{5 5}$ & $\mathbf{6 8}$ & $\mathbf{1 1}$ \\
\hline
\end{tabular}

Tabela 4 - Animacidade do sujeito no registro formal

A hipótese de que haveria uma relação entre o tipo de sujeito (animado ou não animado) e o verbo de mudança de estado escolhido para compor a construção foi confirmada em relação aos verbos tornar-se e virar, pois a maioria dos dados apresentou sujeito não animado (embora tenha havido pouca diferença em relação a virar). Já com o verbo ficar, a hipótese não foi confirmada, pois houve maior ocorrência de sujeitos não animados. Nota-se, então, que há similaridade entre as três construções no que se refere ao tipo de sujeito.

Quanto ao registro informal, obtiveram-se os seguintes resultados (tabela 5):

\begin{tabular}{|l|c|c|c|}
\hline \multicolumn{1}{|c|}{ Registro informal } & FICAR & TORNAR-SE & VIRAR \\
\hline SUJ. ANIMADO & $\underline{\mathbf{4 4}}$ & $\underline{\mathbf{0 4}}$ & $\underline{\mathbf{0 4}}$ \\
\hline SUJ. NÃO ANIMADO & 21 & 03 & 01 \\
\hline TOTAL: & $\mathbf{6 5}$ & $\mathbf{0 7}$ & $\mathbf{0 5}$ \\
\hline
\end{tabular}

Tabela 5 - Animacidade do sujeito no registro informal 
No registro informal, os resultados mostraram-se diferentes. Com ficar, destacou-se o sujeito animado, confirmando a hipótese de que ocorreriam mais sujeitos animados com esse verbo integrado à construção. Já com tornar-se e virar, predominou sujeito animado, embora com pouca diferença quantitativa em relação ao não animado, não confirmando a hipótese inicial da pesquisa.

Somando os resultados do registro formal aos do registro informal, obtiveram-se os seguintes resultados (tabela 6 e tabela 7):

\begin{tabular}{|l|c|c|c|}
\hline & FICAR & TORNAR-SE & VIRAR \\
\hline PREDICATIVO SN & 0 & $\underline{\mathbf{4 7}}$ & $\underline{\mathbf{1 5}}$ \\
\hline PREDICATIVO SADJ & $\underline{\mathbf{1 2 0}}$ & 28 & 01 \\
\hline TOTAL: & 120 & $\mathbf{7 5}$ & 16 \\
\hline
\end{tabular}

Tabela 6 - Tipo de sintagma predicativo nos dois registros

\begin{tabular}{|l|c|c|c|}
\hline & FICAR & TORNAR-SE & VIRAR \\
\hline SUJ. ANIMADO & $\underline{\mathbf{6 7}}$ & 18 & $\underline{\mathbf{0 8}}$ \\
\hline SUJ. NÁO ANIMADO & 53 & $\underline{\mathbf{5 7}}$ & $\underline{\mathbf{0 8}}$ \\
\hline TOTAL: & $\mathbf{1 2 0}$ & $\mathbf{7 5}$ & $\mathbf{1 6}$ \\
\hline
\end{tabular}

Tabela 7 - Animacidade do sujeito nos dois registros 
De acordo com os resultados até aqui, são estabelecidos os padrões construcionais da construção relacional de mudança de estado com os verbos ficar, tornar-se e virar:

(i) Sujeito animado + FICAR + SAdj.;

(ii) Sujeito não animado + TORNAR-SE + SN;

(iii) Sujeito animado + VIRAR + SN;

(iv) Sujeito não animado + VIRAR + SN.

Para ilustrar esses padrões construcionais, seguem alguns dados:

(8) "Por exemplo, se estivessem voando as formigas que costumam comer, como içás e saúvas, ou se fosse época de tinguijar o rio, os estudantes ficariam livres para ir atrás das formigas e peixes."

(9) "A obesidade tornou-se um grande desafio de saúde global, e a doença hoje é considerada como a epidemia do século XXI."

(10) "Em indústrias que visam gerar óleo de coco virgem - mais comuns em países estrangeiros -, de acordo com Tripetchkul et al. (2010), 80\% da água utilizada vira resíduo nas formas de soro de leite e água de lavagem."

(11) "O atacante Berrío, por exemplo, virou solução na Ilha e foi muito bem. Com a volta de Éverton, que estava gripado, a dupla pode atuar pelas pontas ao lado de Guerrero, e Diego chegar de trás."

Em (8), a construção com ficar apresenta sujeito animado ("os estudantes") e predicativo sob a forma de SAdj. ("livres"). Em (9), o sujeito é não animado ("a obesidade") e o predicativo 
aparece sob a forma de SN ("um grande desafio de saúde global"). Em (10), o sujeito também é não animado ("80\% da água utilizada") e o predicativo também apareceu sob a forma de SN ("resíduo"), configurando um padrão bastante semelhante ao de tornar-se. Já em (11), a construção com virar apresenta sujeito animado ("O atacante Berrío") e predicativo sob a forma de SN ("solução").

\subsection{Análise dos testes de percepção/atitudes linguísticas}

A segunda etapa da pesquisa consistiu na aplicação de dois testes de atitudes a 10 participantes leigos. No primeiro teste, foram apresentados 12 trechos retirados dos corpora, sendo 6 trechos do registro formal e 6 do registro informal. Os verbos ficar, tornar-se e virar foram substituídos por lacunas e os participantes deveriam marcar a(s) opção(ões) que julgassem mais adequada(s) e depois justificar, opcionalmente. A maioria dos participantes não justificou.

O primeiro teste teve por objetivo identificar a relação entre o verbo escolhido para compor a construção e o registro (formal/informal).

A tabela 8 apresenta a distribuição dos verbos escolhidos pelos participantes em cada trecho no primeiro teste aplicado. 


\begin{tabular}{|l|l|l|l|}
\hline \multicolumn{1}{|c|}{ Trechos } & FICAR & TORNAR-SE & VIRAR \\
\hline A (formal) & $\underline{\mathbf{7}}$ & 3 & 0 \\
\hline $\mathrm{B}$ (formal) & 1 & $\underline{\mathbf{9}}$ & 0 \\
\hline $\mathrm{C}$ (informal) & $\underline{\mathbf{9}}$ & 1 & 0 \\
\hline $\mathrm{D}$ (informal) & 0 & $\underline{\mathbf{6}}$ & $\mathbf{5}$ \\
\hline $\mathrm{E}$ (formal) & 4 & $\underline{\mathbf{6}}$ & 0 \\
\hline $\mathrm{F}$ (formal) & 0 & $\underline{\mathbf{8}}$ & 2 \\
\hline $\mathrm{G}$ (informal) & $\underline{\mathbf{1 0}}$ & 0 & 0 \\
\hline $\mathrm{H}$ (informal) & $\underline{\mathbf{9}}$ & 1 & 0 \\
\hline $\mathrm{I}$ (formal) & 0 & $\underline{\mathbf{7}}$ & 3 \\
\hline $\mathrm{J} \mathrm{(informal)}$ & $\underline{\mathbf{1 0}}$ & 0 & 0 \\
\hline K (formal) & 0 & $\underline{\mathbf{8}}$ & 3 \\
\hline L (informal) & 0 & $\mathbf{2}$ & $\underline{\mathbf{8}}$ \\
\hline
\end{tabular}

Tabela 8 - Análise dos trechos quanto ao verbo escolhido

Um participante marcou dois verbos no trecho $D$, outro participante marcou dois verbos no trecho $\mathrm{K}$ e todos os outros optaram apenas por marcar um verbo em cada trecho.

Quanto aos resultados da relação entre registro (grau de formalidade) e o verbo escolhido para compor as construções, chegou-se à tabela 9:

\begin{tabular}{|l|l|l|l|}
\hline \multicolumn{1}{|c|}{ Registro } & \multicolumn{1}{c|}{ FICAR } & \multicolumn{1}{c|}{ TORNAR-SE } & \multicolumn{1}{c|}{ VIRAR } \\
\hline Formal & 12 & $\underline{\mathbf{4 1}}$ & 8 \\
\hline Informal & $\underline{\mathbf{3 7}}$ & 10 & $\underline{\mathbf{1 3}}$ \\
\hline
\end{tabular}

Tabela 9 - Relação entre registro e verbo

Como se pode observar na tabela 9, há maior ocorrência de tornar-se no registro formal e de ficar e virar no registro informal.

Nesse primeiro teste, apenas houve justificativa dos trechos C (um participante), D (um participante), G (dois participantes), 
H (dois participantes), I (um participante), J (dois participantes), K (dois participantes) e L (três participantes).

Serão reproduzidos os trechos e comentadas as justificativas dadas por cada participante:

Trecho C) "O chuveiro frio durante toda a nossa estadia. Questionamos a recepção que afirmou que não adiantava trocar de quarto já que o prédio INTEIRO estava com água fria."

Com qual dos seguintes verbos você completaria a lacuna no trecho C? (Você pode marcar mais de uma opção, se julgar pertinente).

( ) ficou

( ) tornou-se

( ) virou

Um participante marcou o verbo "ficou" e justificou que apenas com esse verbo não fica estranho o entendimento da situação ocorrida.

Trecho D) "Realizar o sonho de conhecer o Rio demorou alguns anos, mas quando o sonho realidade, caí de paixão por esta cidade, já voltei 3 vezes e nesta semana volto pela 4a vez."

Com qual dos seguintes verbos você completaria a lacuna no trecho D? (Você pode marcar mais de uma opção, se julgar pertinente).
( ) ficou
( ) se tornou
( ) virou

Outro participante marcou o verbo "se tornou" e deu a justificativa de que "soa melhor". 
Trecho G) " encantada com a naturalidade de Parati, é realmente um sonho! Além, claro, do Cristo Redentor, Pão de Açúcar, Copacabana, dentre outros pontos."

Com qual dos seguintes verbos você completaria a lacuna no trecho G? (Você pode marcar mais de uma opção, se julgar pertinente).
( ) Fiquei
( ) Tornei-me
( ) Virei

Um participante escolheu o verbo "Fiquei" para completar o trecho e justificou dizendo que "Tornei-me" seria típico de uma pessoa muito formal e "Virei" não seria possível. Já outro participante também marcou "Fiquei", mas disse que é porque dá "mais intensidade".

Trecho H) "Sou Carioca, tenho 35 anos e pela primeira vez, fui conhecer o Pão de Açúcar e o Corcovado. deslumbrada com tamanha beleza que é meu Rio de Janeiro, aquele que eu conhecia, apenas por ouvir falar ou assistir na tv."

Com qual dos seguintes verbos você completaria a lacuna no trecho H? (Você pode marcar mais de uma opção, se julgar pertinente).

( ) Fiquei

( ) Tornei-me

( ) Virei

Um participante escolheu o verbo "Fiquei" para completar o trecho e justificou que "Tornei-me" seria típico de uma pessoa muito formal e "Virei" não seria possível (como na justificativa do trecho G). Outro participante também marcou o verbo "Fiquei", mas deu a justificativa de que ele demonstra mais o estado em que a pessoa está. 
Trecho I) "A obesidade um grande desafio de saúde global, e a doença hoje é considerada como a epidemia do século XXI."

Com qual dos seguintes verbos você completaria a lacuna no trecho I? (Você pode marcar mais de uma opção, se julgar pertinente).

( ) ficou

( ) tornou-se

( ) virou

Um participante marcou a opção "tornou-se" e justificou que a escolha por outro verbo talvez mudasse a intenção da frase.

Trecho J) "Excelente vista, pena que o tempo fechou após chegarmos na segunda plataforma, muito vento e barulho de trovões, pelo risco devido aos ventos eu não tive coragem de seguir da segunda plataforma para a terceira, mas meu marido foi e o bondinho alguns minutos parado no meio do percurso entre a segunda e a terceira plataforma, mas ele não se abateu e aproveitou a paisagem para tirar muitas fotos."

Com qual dos seguintes verbos você completaria a lacuna no trecho J? (Você pode marcar mais de uma opção, se julgar pertinente).

( ) ficou

( ) tornou-se

( ) virou

Um participante marcou o verbo "ficou" e justificou que se encaixa melhor porque o bondinho se movimenta. Outro participante também marcou o verbo "ficou" e justificou que ele traz mais sentido à frase. 
Trecho K) “Ex-borracheiro estuda com $200 \mathrm{~kg}$ de resumos por 4 anos e juiz no DF."

Com qual dos seguintes verbos você completaria a lacuna no trecho K? (Você pode marcar mais de uma opção, se julgar pertinente).

( ) fica

( ) torna-se

( ) vira

Um participante marcou os verbos "torna-se" e "vira" e justificou dizendo que "vira" seria mais utilizado na fala do cotidiano e que "torna-se" seria mais usado na escrita formal. Já outro participante também marcou o verbo "torna-se", mas justificou que "ninguém fica juiz" nem "vira juiz", mas "torna-se juiz" devido a um grande esforço durante a vida.

Trecho L) "Alegria medo: Com a chegada da água em açude do Sertão, população teme parede romper."

Com qual dos seguintes verbos você completaria a lacuna no trecho L? (Você pode marcar mais de uma opção, se julgar pertinente).

( ) ficou

( ) tornou-se

( ) virou

Um participante marcou o verbo "virou" e justificou que tal verbo "passa melhor" o sentido de transformação da situação. Outro participante marcou o mesmo verbo e justificou que há uma mudança de coisas opostas. Um terceiro participante marcou o mesmo verbo e deu a justificativa de que ele traz um sentido "mais fácil" à frase. 
Embora a minoria dos participantes tenha justificado suas respostas, é possível inferir que houve uma associação entre o verbo e o registro ("tornar-se" seria mais formal e "virar" mais informal) e que os participantes perceberam a noção de mudança mais duradoura, que demanda um processo mais gradual, no uso do verbo "tornar-se". Assim, pode-se concluir que a escolha por um dos verbos em estudo para compor a construção relacional de mudança de estado é motivada, dentre outros fatores, pelo grau de formalidade (registro formal ou informal), confirmando uma das hipóteses iniciais da pesquisa.

No segundo teste, foram apresentados 6 trechos (diferentes dos utilizados no teste 1) dos corpora, sendo 2 com ficar, 2 com tornar-se e 2 com virar, para que os participantes julgassem o sentido da construção como mais permanente/duradouro, mais transitório/passageiro ou híbrido e justificassem, opcionalmente. A maioria dos participantes também não justificou as respostas.

A tabela 10 ilustra os resultados gerais do teste:

\begin{tabular}{|l|l|l|l|}
\hline \multicolumn{1}{|c|}{ Trechos } & \multicolumn{1}{c|}{ +permanente } & \multicolumn{1}{c|}{ +transitório } & \multicolumn{1}{c|}{ Híbrido } \\
\hline A (ficar) & 02 & $\underline{\mathbf{0 7}}$ & 01 \\
\hline B (tornar-se) & $\underline{\mathbf{0 8}}$ & 01 & 01 \\
\hline C (ficar) & 03 & $\underline{\mathbf{0 6}}$ & 01 \\
\hline D (tornar-se) & $\underline{\mathbf{1 0}}$ & 0 & 0 \\
\hline E (virar) & $\underline{\mathbf{0 6}}$ & 02 & 02 \\
\hline F (virar) & $\underline{\mathbf{0 6}}$ & 01 & 03 \\
\hline
\end{tabular}


Quanto aos resultados da relação entre aspecto (mais permanente ou mais transitório) e o verbo escolhido para compor as construções, chegou-se à tabela 11:

\begin{tabular}{|l|l|l|l|}
\hline \multicolumn{1}{|c|}{ Verbos } & \multicolumn{1}{c|}{ +permanente } & \multicolumn{1}{c|}{ +transitório } & \multicolumn{1}{c|}{ Híbrido } \\
\hline FICAR & 05 & $\underline{\mathbf{1 3}}$ & 02 \\
\hline TORNAR-SE & $\underline{\mathbf{1 8}}$ & 01 & 01 \\
\hline VIRAR & $\underline{\mathbf{1 2}}$ & 03 & 05 \\
\hline
\end{tabular}

Tabela 11 - Relação entre aspecto e verbo

Segundo tais resultados, os participantes reconhecem as construções com ficar como mais transitórias/passageiras e as com tornar-se e virar, mais permanentes/duradouras.

Quanto ao segundo teste, houve justificativa dos trechos A (três participantes), B (um participante), C (um participante), D (três participantes), E (um participante) e $F$ (dois participantes). Serão reproduzidos os trechos e comentadas as justificativas dadas por cada participante:

Trecho A) "Também gostaria de registrar o péssimo secador, que funciona 2 minutos e fica desligado por $\mathbf{1 0}$ minutos. Liguei na recepção e não tinha outro tipo de secador para emprestar."

O trecho destacado indica uma mudança de estado com sentido:

( ) mais permanente, duradouro

( ) mais transitório, passageiro

( ) híbrido (nem permanente, nem transitório)

Um participante marcou que o sentido é híbrido, pois o secador não funciona exatamente do mesmo jeito todas as vezes. Outro participante marcou que o sentido é mais 
transitório, pois o secador ora funciona, ora não funciona. Um terceiro participante marcou que o sentido é mais transitório também e justificou que o secador não fica ligado o tempo necessário.

A presença do adjunto adverbial "por 10 minutos" pode ter influenciado na reposta da maioria dos participantes, uma vez que denota um tempo curto (passageiro).

Trecho B) "Dessa forma, os alunos tornam-se sujeitos do seu discurso quando internalizam o conhecimento a partir de diálogos criativos."

O trecho destacado indica uma mudança de estado com sentido:

( ) mais permanente, duradouro

( ) mais transitório, passageiro

( ) híbrido (nem permanente, nem transitório)

Um participante marcou que o sentido é mais permanente, pois "dá a entender" que é algo para sempre.

Trecho C) "Fui ao Rio de Janeiro com minha família, e fiquei surpresa com a cidade."

O trecho destacado indica uma mudança de estado com sentido:

( ) mais permanente, duradouro

( ) mais transitório, passageiro

( ) híbrido (nem permanente, nem transitório)

Um participante marcou que o sentido é mais permanente, pois a pessoa guardará a imagem da cidade para sempre. 
Trecho D) "Para Mara a separação conjugal foi algo conflituoso, onde esta acabou transferindo sua angústia para a filha e, transformando assim, em apego exagerado." Desta forma mãe e filha tornam-se dependentes uma da outra.

O trecho destacado indica uma mudança de estado com sentido:

( ) mais permanente, duradouro

( ) mais transitório, passageiro

( ) híbrido (nem permanente, nem transitório)

Todos os participantes que justificaram marcaram o sentido mais permanente. O primeiro justificou que a separação causou dependência da filha porque foi traumática; o segundo justificou que o trecho demonstra que a situação vivida atualmente vem acontecendo permanentemente; o terceiro deu a justificativa de que há um elo permanente e duradouro porque uma se apoiou na outra, aumentando os laços afetivos.

Trecho E) "Em indústrias que visam gerar óleo de coco virgem - mais comuns em países estrangeiros -, de acordo com Tripetchkul et al. (2010), 80\% da água utilizada vira resíduo nas formas de soro de leite e água de lavagem."

O trecho destacado indica uma mudança de estado com sentido:

( ) mais permanente, duradouro

( ) mais transitório, passageiro

( ) híbrido (nem permanente, nem transitório)

Um participante marcou que o sentido é mais permanente porque é um fato confirmado. 
Trecho F) "A igreja virou comércio ou estou enganado? Vejo na televisão pastores pedindo oferta acima de 100, 200, 500 reais e assim por diante; pastores falando mais de política do que de Deus..."

O trecho destacado indica uma mudança de estado com sentido:

( ) mais permanente, duradouro

( ) mais transitório, passageiro

( ) híbrido (nem permanente, nem transitório)

Um participante marcou que o sentido é mais permanente porque a ganância pelo dinheiro é permanente. Outro participante marcou o mesmo sentido e justificou que o trecho traduz a "situação corriqueira" em que vivemos hoje e que sempre acontece assim.

Com base nas justificativas dos participantes, é possível inferir que houve uma identificação das construções com tornar-se e virar como mais permanentes/duradouras. Quanto às com ficar, não houve consenso nas justificativas, pois uma foi considerada mais permanente e a outra mais transitória. Assim, pode-se concluir que a escolha por um dos verbos em estudo para compor a construção relacional de mudança de estado é motivada também pelo aspecto (mais permanente ou mais transitório), confirmando outra hipótese inicial da pesquisa. 


\section{CONSIDERAÇÕES FINAIS}

Neste trabalho, buscou-se descrever a variação na construção relacional de mudança de estado com os verbos ficar, tornar-se e virar no PB.

De acordo com os resultados, as hipóteses iniciais da pesquisa foram confirmadas. Quanto à análise dos dados coletados, foi confirmada uma relação entre o sintagma predicativo e o verbo escolhido para compor a construção, sendo o verbo ficar mais utilizado com predicativo sob a forma de SAdj. e tornar-se e virar com predicativo sob a forma de SN; entre o tipo de sujeito e o verbo selecionado, sendo ficar mais compatibilizado a sujeitos animados e tornar-se e virar mais compatibilizados a sujeitos não animados.

Quanto à análise dos testes de percepção/atitudes linguísticas, foi confirmado que a escolha por um dos três verbos (ficar, tornar-se ou virar) é motivada por fatores aspectuais/semânticos e pragmáticos. O verbo tornar-se é mais selecionado para compor construções típicas do registro formal e com sentido/aspecto mais permanente; virar é mais selecionado para integrar construções do registro informal e com sentido/aspecto mais permanente; ficar é mais selecionado para compor construções típicas do registro informal (embora também ocorra bastante em situações 
formais, como os dados mostram) e com sentido/aspecto mais transitório. Também se concluiu que as construções com tornar-se e virar apresentam muitas similaridades, diferenciando-se apenas quanto ao registro.

Com base na abordagem construcional e nos resultados obtidos até aqui, propõe-se uma rede para representar os padrões da construção relacional de mudança de estado com os verbos ficar, tornar-se e virar estabelecidos nesta pesquisa:

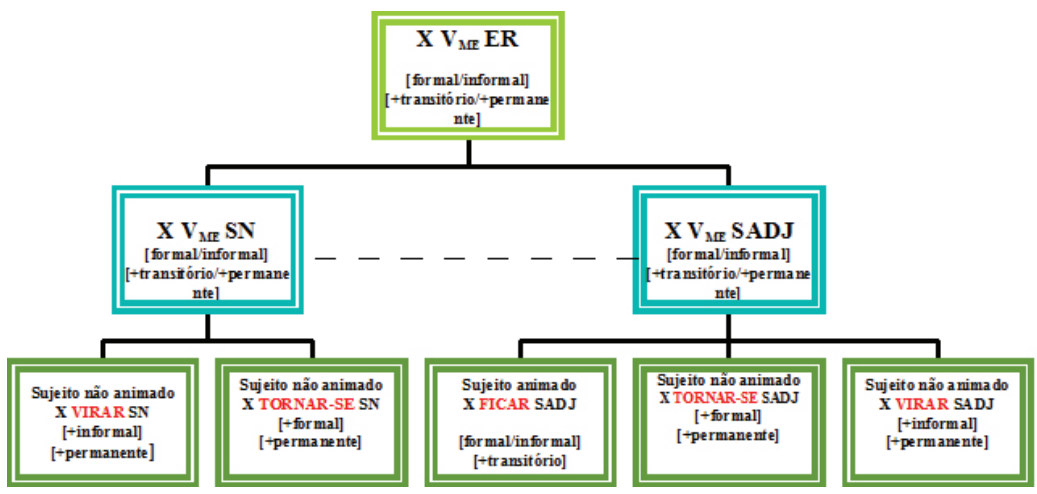

Diagrama 1 - Padrões construcionais

A rede apresentada mostra, em um nível mais esquemático, a construção formada por sujeito $(X)$, verbo de mudança de estado $\left(\mathrm{V}_{\mathrm{ME}}\right)$ e estado resultante (ER), com registro formal ou informal e aspecto mais transitório ou mais permanente. No nível intermediário, o estado resultante pode ser representado por um sintagma nominal (SN) ou por um sintagma adjetival (SADJ). 
Por fim, as microconstruções mostram os verbos (ficar, tornarse e virar) que podem preencher o segundo slot da construção em jogo. Para que tal preenchimento seja realizado, é necessário levar em consideração a animacidade do sujeito (animado ou não animado), o grau de formalidade (contexto formal ou informal) e o aspecto (permanente ou transitório) da construção.

Pretende-se expandir os corpora de análise e buscar outros verbos que possam integrar tal construção, a fim de descrever uma parcela ainda maior dessa rede construcional, contribuindo, assim, para uma descrição mais detalhada e efetiva da construção relacional de mudança de estado.

\section{REFERÊNCIAS}

BYBEE, Joan (2013). "Usage-based theory and exemplar representation of constructions". In: HOFFMAN, T.; TROUSDALE, G. (Eds.). The Oxford Handbook of Construction Grammar. Oxford: University Press.

(2010). Language, usage and cognition. New York: Cambridge University Press.

(2006). \& EDDINGTON, David. "A usage-based approach to Spanish verbs of 'becoming'”. Language 82(2), 323-355.

CROFT, William (2001). Radical Construction Grammar. Oxford, Oxford University Press.

ESTEVES, Giselle Aparecida Toledo (2008). Construções com dar +Sintagma Nominal: a gramaticalização desse verbo e a alternância entre perífrases verbo-nominais e predicadores simples. (Dissertação de Mestrado). Rio de Janeiro: UFRJ/FL.

FASOLD, Ralph (1987 [1984]). The Sociolinguistics of Society. vol.1. New York, USA: B. Blackwell. p.147-179. 
FERREIRA, Bruna Gois Pavão (2015). Construção relacional: estado, mudança e resultado. (Dissertação de Mestrado). UFRJ. Rio de Janeiro. GOLDBERG, Adele E (1995). Constructions : a construction grammar approach to argument structure. The University of Chicago Press, Chicago and London.

(2013). "Constructionist approaches". In: HOFFMANN, Thomas \& TROUSDALE, Graeme. The Oxford Handbook of Construction Grammar. USA: Oxford University Press.

PAVÃO, Bruna Gois; VIEIRA, Marcia dos Santos Machado (2013). "Predicações com os verbos relacionais ser e estar". Diadorim: Revista de Estudos Linguísticos e Literários, vol.14. In http://www.revistadiadorim. letras.ufrj.br. Acesso em Dez.2013.

TRAUGOTT, Elizabeth Closs. \& TROUSDALE, Graeme (2013). Constructionalization and Construction changes. Great Britain: Oxford University Press.

\section{ANEXOS}

\section{1) Artigos acadêmicos:}

http://revistaseletronicas.pucrs.br/ojs/index.php/faenfi https://www.revistas.ufg.br/reec/issue/view/\%5BREEC\%5D\%20 Vol.13\%20N\%C2\%BA.1

http://www.seer.ufu.br/index.php/cieng/issue/view/1362/showToc http://www.educacaoepesquisa.fe.usp.br/?author=1

\section{2) Avaliações de viajantes e reclamações de consumidores:}

https://www.tripadvisor.com.br/Attractions-g303506-Activities-Rio_de_ Janeiro_State_of_Rio_de_Janeiro.html [Acesso em 04.Jan.17 e 06.Jan.17] http://www.booking.com/city/br/rio-de-janeiro.pt-br.html [Acesso em 19.Jan.17]

http://www.mundi.com.br/Avaliacoes-Rio-de-Janeiro-2713590.html [Acesso em 09.Jan.17]

http://www.reclameaqui.com.br/busca/?q=celulares [Acesso em 23.Jan.17] 


\section{3) Jornais O Globo e Extra:}

https://oglobo.globo.com/

https://extra.globo.com/

Bruna Gois Pavão Ferreira é Doutoranda em Letras Vernáculas Língua Portuguesa, pela UFRJ e Mestra em Letras Vernáculas - Língua Portuguesa. Participante do Projeto PREDICAR - Formação e expressão de predicados complexos: estabilidade, variação e mudança construcional. E-mail: brunagpavao@hotmail.com. CV Lattes: http://lattes.cnpq. br/0359514910368479 